\title{
CAEM (Peru) e ESG (Brasil): doutrinas de Segurança e Desenvolvimento
}

CAEM (Peru) and ESG (Brazil): security and development doctrines

Êça Pereira da Silva 
Resumo: Este artigo compara as doutrinas de segurança nacional desenvolvidas no CAEM (Centro de Altos Estudos Militares) peruano e na ESG (Escola Superior de Guerra) brasileira. Primeiramente, apresentar-se-á um panorama bibliográfico sobre as doutrinas militares do Brasil e do Peru, em seguida mostraremos como as influências francesa e estadunidense atuaram em cada uma das escolas militares. A seguir, analisaremos as apresentações realizadas nas duas academias militares sobre suas respectivas doutrinas, destacando como as circunstâncias e as demandas sociais percebidas pelos militares acarretaram diferentes soluções para o problema da segurança - defesa: de um lado, a doutrina da segurança integral e, de outro, a segurança nacional. Esta análise comparativa visa compreender como escolas militares com influências semelhantes construíram diferentes respostas para o que consideravam o desafio da subversão comunista. Palavras-chave: Segurança nacional; Segurança integral; ESG; CAEM.

Abstract: This article compares the national security doctrines developed in the Peruvian CAEM and the Brazilian ESG. First, we will present a bibliographic overview of the military doctrines of Brazil and Peru, then we will show how the French and American influences acted in each of the military schools. Next, we will analyze as sources the presentations made in the two military academies about their respective doctrines, highlighting how the circumstances and social demands perceived by the military led to different solutions to the problem of security - defense: on the one hand, the doctrine of integral security and on the other, national security. This comparative analysis aims to understand how military schools with similar influences built different responses to what they considered the challenge of communist subversion.

Keywords: National security; Integral security; ESG; CAEM. 


\section{Introdução}

Há um intenso debate sobre o papel das doutrinas militares nos golpes dos anos 1960-1970. Aqui apresentaremos as principais linhas interpretativas a fim de situarmos o papel particular do CAEM (Centro de Altos Estudos Militares) e da ESG (Escola Superior de Guerra) na elaboração das doutrinas militares peruana e brasileira, que embasaram os golpes nos dois países na década de 1960, por fim, analisaremos comparativamente tais doutrinas.

Primeiramente, é preciso diferenciar dois conceitos: segurança e defesa. $\mathrm{O}$ primeiro está ligado à precaução contra ameaças internas ao Estado, enquanto o segundo se refere às ameaças externas. Assim, as Forças Armadas dos Estados-nações foram instituídas para agir em defesa do território do Estado, no entanto, com a Guerra Fria, a segurança passou a ser um problema militar.

Sendo assim, mencionaremos as distintas perspectivas sobre a DSN para melhor compreendermos a função que as doutrinas elaboradas nas escolas militares e suas especificidades, visto que tanto a doutrina de segurança nacional desenvolvida pela ESG no Brasil, quanto a doutrina de segurança integral produzida pelo CAEM no Peru, são entendidas como um conjunto de ideias que remetem a um projeto de organização social, fruto de concepções ideológicas de seus produtores, e que organizam e explicitam um projeto político. Ressaltaremos, ainda, que o tema das doutrinas militares é fulcral para a compreensão das políticas adotadas pelos regimes militares. Se alguns autores situam as doutrinas como ideologias e as escolas militares como centros produtores de ideologias, outros, as analisam na dinâmica das casernas, e de como se relacionaram aos projetos políticos encampados pelos militares quando tomaram o poder.

Analisaremos, assim, as doutrinas enquanto expressões de projetos de Estado, frutos de ideias que orientaram práticas políticas. Ao abordar cada uma delas buscaremos comparar aspectos comuns e suas especificidades com o intuito de compreender, em profundidade, as instituições objetos de estudo - o CAEM e a ESG.

\section{Doutrinas militares: debate bibliográfico}

Samuel Huntington (1996) afirmou que a segurança deveria ser estruturada em três instâncias: a militar, que objetiva minimizar ameaças externas às instituições e/ou território; a interna, cujo foco deveria ser aqueles que visam 
destruir o Estado por dentro; e, por último, a situacional, que deveria combater as mudanças políticas drásticas que reduziriam o poder do Estado.

Há alguns pesquisadores, como René Dreifuss (1981), Francisco Ferraz (1997), Nilo Oliveira (2010), Eliézer Rizzo de Oliveira (1976, 1987), Joseph Comblin (1980), entre outros, para os quais as doutrinas de segurança nacional (DSN) são discursos ideológicos, construídos nas escolas militares, que representam uma leitura particular da realidade apresentada como universal. Para Dreifuss (1981), a ESG era um reduto de compartilhamento de ideias entre militares e tecno-empresários e, a DSN, seria o elo de articulação entre interesses militares e civis, ou seja, defender a nação do comunismo e implantar um projeto de desenvolvimento capitalista subordinado aos interesses multinacionais.

Segundo Ferraz (1997), a DSN elaborada na ESG consistia numa prática antiga: a aliança entre elites civis e militares para o controle do Estado. Para o historiador, a ESG foi um lugar de articulação das ideias estadunidenses fortalecidas com a experiência da FEB às ideias autoritárias dos anos 1920 e 1930, cujas matrizes eram o pensamento de Oliveira Vianna e Alberto Torres.

O historiador Nilo Oliveira (2010) analisou a DSN gestada na ESG como uma ideologia que reuniu ideias autoritárias para submeter os trabalhadores, intensamente mobilizados nos últimos anos do governo eleito de Vargas, fortalecendo vínculos econômicos com os centros capitalistas internacionais. Para este autor quanto mais acentuada a dependência de tais centros do capitalismo, mais o aspecto coercitivo da DSN foi enfatizado para manter ordem.

Na mesma linha, Eliezer Oliveira (1987) afirmou que a DSN lastreou a elaboração de um projeto de hegemonia política do grupo reunido na ESG. Portanto, ao justificarem suas ações pela "segurança nacional”, apontando “objetivos, meios e fins nacionais”, procuraram legitimá-las. O pesquisador conclui, ainda, que a DSN, por utilizar a segurança para justificar a restrição dos debates sobre os rumos da nação às elites, levou à centralização do poder no executivo federal.

Ainda no que se refere às análises sobre as DSN's, há o estudo de Joseph Comblin. Tal estudo afirma que o anticomunismo era o motor da construção doutrinária militar em nosso continente, elaborada sob grande influência dos EUA, sobretudo no Brasil, a partir dos anos 1940. A crítica do autor à DSN centrase no fato desta reduzir os problemas sociais à lógica bélica, estendendo-a à política, instância que deveria servir para a negociação e o diálogo.

Para Comblin (1980), a DSN brasileira não passou de uma nacionalização 
daquela produzida no War College. Ao comparar a doutrina militar brasileira à peruana, o autor verificou que a diferença entre ambas estaria no fato de que a primeira seria completamente tributária das ideias estadunidenses, enquanto a segunda seria elaboração autêntica dos peruanos. No entanto, o próprio autor indica que o ideário estadunidense, de certo modo, pesou sobre a doutrina andina ao manter-se na esfera do capitalismo.

A historiadora Maria Selma Rocha (1996) analisou as disputas em torno do discurso doutrinário da ESG nos anos 1970, contribuindo para enfatizar a dinâmica da DSN, que nos “marcos conservador e autoritário”, transformouse ao longo da década de 1970 para adaptar-se às conjunturas e, mesmo indiretamente, responder ao discurso opositor.

A pesquisa de Rocha (1996), apresentou, ainda, duas grandes linhas às análises sobre a atuação política das Forças Armadas no Brasil. De um lado, a dos pesquisadores que enfatizam os interesses econômicos civis presentes da ESG, ou seja, os conflitos sociais externos à instituição, são as interpretações do militarismo classificadas como instrumentais, ou seja, as Forças Armadas teriam sido instrumento de ação da burguesia ligada às multinacionais, sendo suas motivações principalmente econômicas. De outro lado, há os trabalhos que focam as dinâmicas internas às Forças Armadas, abordando-as em sua autonomia em relação à sociedade - a chamada perspectiva organizacional.

Em busca da identidade: o exército e a política na sociedade brasileira, de Edmundo Coelho (2000), é uma referência da perspectiva organizacional. O sociólogo definiu doutrina militar como um conjunto de ideias sistematizadas sobre concepção e finalidades da organização militar. Para o autor, a DSN tinha as seguintes funções: a) produzir o consenso nas Forças Armadas, para eliminar disputas internas; b) fazer com que os governos se comprometessem com a segurança nacional, invertendo a lógica democrática de que as Forças Armadas deveriam lealdade ao governo eleito; c) congregar valores militares tradicionais (honra, coragem, heroísmo) às ideias de modernização e do saber técnico trazidas pelo contato com os estadunidenses; d) incluir os militares na organização política, ao atrelar as noções de segurança e desenvolvimento, estabelecendo como deveriam ser as relações entre estes e os civis.

Segundo o sociólogo Rodríguez Beruff (1983), a ideologia militar pode ser percebida nas formulações mais abstratas da doutrina, sendo que essa define de modo específico o papel político da instituição militar no Estado e, ao mesmo tempo, apresenta parâmetros de como dirimir diferenças ideológicas internas às Forças Armadas. O pesquisador afirmou que a doutrina militar é uma parte 
específica da ideologia dominante, pois articula os interesses mais gerais às especificidades da instituição militar, culminando num projeto de Estado, cerne de toda doutrina militar. Para o sociólogo, as duas leituras excludentes sobre os militares são nocivas à compreensão de seu papel: de um lado, aqueles que analisam os militares dentro de suas próprias questões institucionais e se esquecem que estas só existem em relação às questões da sociedade; de outro, aqueles estudiosos que entendem as questões da caserna como meras extensões dos debates sociais mais amplos, minimizando as particularidades dos militares.

Os autores que escrevem sobre as DSN's, de algum modo referem-se aos estudos do cientista político Alfred Stepan, apesar das muitas críticas sobre suas teses do antigo "poder moderador" e do "novo profissionalismo" militar. O autor estadunidense indicou especificidades nos casos do Brasil e do Peru. No caso do Brasil, Stepan explicou que a doutrina da ESG propunha a SN através da maximização da produção econômica simultaneamente à minimização dos conflitos internos, o que demandaria um "governo forte" para planificação sólida (STEPAN, 1974).

Para o caso peruano, Stepan afirmou que o CAEM formulou um certo consenso entre os militares, mas não organizou o grupo que tomou o poder em 1968. Tal consenso consistia numa concepção de governo que o autor chamou de “estatista orgânica”, ou seja, um projeto de sociedade organizada pelo Estado que formaria uma unidade não conflitante (STEPAN, 1980).

As críticas feitas às interpretações de Stepan sobre a atuação dos militares na política latino-americana focam-se em sua orientação teórica: para Coelho (2000), a função moderadora não passa de um mito, uma vez que tal conceito é tão elástico que se tornaria inútil, servindo apenas para justificar as intervenções militares no governo.

O filósofo João Quartim de Moraes (2001) também criticou a tese de Stepan - segundo a qual quanto mais "profissionalizados", melhores condições os militares teriam de intervir no poder político; e também a de Huntington, para quem quanto mais profissionalizados fossem os militares, menos interviriam na política.

Para Moraes (2001), assim como para Ferraz (1997), a função primária das Forças Armadas - fazer uso da violência para defender o Estado - já é política em si mesma, sendo que os oficiais peruanos que tomaram o poder em 1968 seriam comparáveis aos militares nacionalistas brasileiros dos anos 1950, que mobilizaram a campanha pela nacionalização do petróleo, em oposição ao grupo 
da ESG. Este argumento é válido somente se consideramos o nacionalismo destes dois grupos; mas ao comparar-se à formação oferecida pelas duas escolas - O CAEM e a ESG, é justamente a diferença de como incorporaram os mesmos pressupostos militares que interessa aqui.

De acordo com Tapia Valdés (1980), a DSN consistia num conjunto de ideias que informava as ações políticas dos militares e manifestava um projeto político-econômico-militar que era diferente, mas não antagônico ao projeto de dominação burguesa, que se daria pela via democrática. Para o autor, o caso do regime militar peruano, instalado em 1968, não era tributário da DSN, sendo melhor classificado como “militarismo populista”. Segundo Tapia Valdés (1980), os militares no Peru formaram uma nova elite, que apelou à mobilização popular para competir pela direção do Estado. No entanto, o pesquisador reconhece que o caso peruano poderia apresentar alguns princípios da DSN.

Por meio da análise de fontes, encontramos indícios que contrastam com a análise do jurista chileno, pois constata-se que havia uma doutrina de segurança integral peruana. Nota-se, também, que os peruanos se valeram dos mesmos conceitos que serviram de base para a DSN brasileira (objetivos nacionais, planificação, entre outros). Contudo, destaca-se que os peruanos elaboraram, de forma distinta dos brasileiros, a relação entre Forças Armadas e sociedade.

Victor Villanueva (1972) esboçou um paralelo entre a doutrina peruana e a brasileira, indicando como similaridade mais evidente o desenvolvimento como objetivo, além do anticomunismo - generalizado pela América Latina, mas "patológico", segundo o autor, no caso brasileiro. O pesquisador destacou as especificidades quanto ao exercício do poder após os golpes: enquanto a ESG brasileira tinha uma aproximação clara das elites, posicionamentos liberais, "pró-yankees", autoritários - por não representarem os anseios populares e ambições subimperialistas no continente, o CAEM teria se distanciado das oligarquias e enfrentado o imperialismo estadunidense com um discurso "neutro" de "nem capitalismo, nem comunismo" e implementado reformas sociais e econômicas para atender às demandas populares.

Para o historiador Toche Medrano (2008), a elaboração de uma doutrina que priorizava o desenvolvimento nacional está relacionada à história do exército peruano nas regiões dos Andes e da Amazônia. De modo que as Forças Armadas incorporaram o papel de agente modernizador da nação, que deveria inserir as populações nas instituições através do serviço militar obrigatório. Portanto, o papel do CAEM como promotor de uma doutrina militar focada no desenvolvimento, teria sido a radicalização de uma função que os militares 
tomaram para si desde o fim do Século XIX, por influência da missão francesa.

Para o pesquisador Dirk Kruijt (2008), a doutrina militar peruana resultou do trabalho dos intelectuais militares - figuras surgidas após a Segunda Guerra Mundial, que ocupavam as direções das escolas de formação para oficiais e dos serviços de inteligência, cuja função era forjar a ideologia militar. Deste modo, o CAEM seria uma instituição responsável pela elaboração doutrinária inspirada pela Teologia da Libertação e pela Comissão Econômica para a América Latina, enquanto a ESG brasileira teria sido tributária do pensamento militar e do liberalismo estadunidense.

Para o cientista político Leal Buitrago, a DSN consiste numa "concepção militar do Estado e do funcionamento da sociedade, que justifica a 'ocupação' das instituições estatais por parte dos militares” (LEAL BUITRAGO, 2003, p. 75). O autor destacou que o Brasil foi o primeiro país a elaborar uma lei de segurança nacional, em 1935. O autor explicou que a ideia de SN teve diferentes funções em cada país do Cone Sul: no Brasil, justificou o golpe contra o governo de João Goulart em 1964; no Peru, uma exceção, frisa, os militares do CAEM criaram uma variante desenvolvimentista da DSN, que justificou os golpes de 1962 e 1968 contra o poder das oligarquias tradicionais atreladas ao capital internacional.

Já para o cientista político mexicano Monteforte Toledo (1973), a contribuição do CAEM para os golpes de 1962 e 1968 foi indireta, ao promover uma postura mais questionadora dos militares. Segundo o autor, para muitos militares que participaram do governo instalado em 1968, o CAEM fora superado pelas medidas da "revolução" e ficado à direita do processo. É justamente o CAEM antes de 1968 que interessa aqui.

\section{França e EUA: referências da guerra total à guerra revolucionária}

A bibliografia é unânime em vincular as DSN ao colonialismo francês e ao anticomunismo estadunidense, por isso analisaremos a relação entre a DSI peruana e a DSN brasileira e às matrizes francesa e estadunidense. Na virada do século XIX para o XX, diversos países da América Latina recorreram às missões europeias para organizar suas Forças Armadas nos moldes mais modernos de então. Naquele momento, tanto o Brasil como o Peru, por diferentes razões, optaram por missões militares francesas, o que não significa que foram unânimes e tampouco que corresponderam exatamente às expectativas dos anfitriões, mas nem por isso sua contribuição foi menos significativa. 
No Brasil, a influência francesa contribuiu para a disseminação do positivismo e do republicanismo entre os militares; eram os oficiais chamados "doutores" ou "bacharéis", segundo José Murilo de Carvalho, homens como Benjamin Constant ou Euclides da Cunha, que não lutaram no Paraguai, mas que possuíam grande letramento, preocupação científica e um pacifismo militante (CARVALHO, 2005).

No Peru, a missão francesa chegou após o fim da Guerra do Pacífico (18791881), na qual, junto com os bolivianos, foram derrotados pelo Chile. Esta guerra foi seguida de uma série de conflitos internos, ao cabo dos quais teve início o processo de modernização das Forças Armadas peruanas. Segundo Toche Medrano, a opção pela França teve motivações diversas: a transposição para a América da rivalidade franco-prussiana (Chile escolhera antes a Prússia); a doutrina militar francesa, que defendia o afastamento dos militares da política - este envolvimento era apontado como importante fator da derrota para os chilenos e também pela idêntica reivindicação de retomada dos territórios perdidos, no caso francês, a Alsácia-Lorena e, para os peruanos, o território ao sul de Tacna, perdido para o Chile (TOCHE MEDRANO, 2008, p. 25).

Para Frederick Nunn (1979), a doutrina desenvolvimentista dos militares peruanos foi consequência da influência francesa. Para Nunn, a ideia de que os militares deveriam ser agentes modernizadores surgira na França, em sua ação colonizadora, e os peruanos teriam adaptado esta ideia a seu próprio contexto: indígenas e camponeses conscritos acessariam o nacionalismo e teriam igualdade de oportunidades para ascensão. Além disso, o progresso material da nação via reforma agrária e integração nacional (construção de estradas) seria alcançado pelo engajamento militar.

Especificamente no CAEM, a influência francesa é identificada em seus dois primeiros diretores, os generais Jose del Carmen Marín Arista e Romero Pardo Marcial. Segundo Toche Medrano (2008), Marín foi o oficial que mais se aproximou do ideal de formação francesa e, paradoxalmente, por isso mesmo percebeu a necessidade de elaboração de uma doutrina própria e da autonomia em relação às potências estrangeiras. Assim, justamente por ter compreendido a lógica francesa, o general Marín identificou como problema do Estado peruano a ausência de planejamento para o desenvolvimento nacional decorrente, entre outros fatores, da ignorância a respeito do interior do território.

O segundo diretor do CAEM, o general Pardo Marcial, visitou a ocupação francesa na Argélia, onde observou as práticas colonialistas. Em 1944 publicou o livreto La Guerra Total, contendo dois artigos, o primeiro de 1941 sobre El 
concepto moderno de defensa nacional e o segundo de 1942, La guerra total y la movilización integral, que explicam algumas concepções doutrinárias posteriormente divulgadas pelo CAEM. Nesta apresentação da doutrina de guerra total feita pelo general Pardo Marcial percebem-se algumas características que marcaram o instituto anos depois, a começar com a preocupação em educar os cidadãos para a defesa nacional. O uso do conceito de “defesa nacional” também deve ser destacado, uma vez que no Brasil, desde 1935, a questão da segurança nacional, com consequente combate ao "inimigo interno" estava colocada, enquanto, no Peru, havia a proposta em educar o cidadão para que defendesse a nação. Outro aspecto destacado é a preocupação com a independência política do país (PARDO MARCIAL, 1944).

Segundo o sociólogo Rodríguez Beruff (1983), o núcleo da doutrina da guerra total consiste em planejar o direcionamento de toda produção do país para o esforço bélico ainda nos tempos de paz; o que levaria à militarização cada vez maior da sociedade civil e à ocupação por militares de tarefas governamentais, pois os esforços sociais e o aparato produtivo seriam pensados, dali em diante, como definidores do sucesso bélico.

A doutrina da guerra total também fez parte do arcabouço de ideias presentes na ESG, a partir da mobilização da Força Expedicionária Brasileira na Segunda Guerra.Assim comoRodríguez Beruff(1983) para o casoperuano,FranciscoFerraz (1997) para o brasileiro, enfatizou a importância da mobilização, fundamental na doutrina da guerra total. Por isso, muitas conferências ministradas ao longo das décadas de 1950 e 1960 na ESG intituladas “mobilização” econômica, financeira, industrial, etc. - relacionaram desenvolvimentismo ao ideário liberal.

O Brasil foi o único país da América do Sul a enviar tropas para lutar sob o comando estadunidense na Segunda Guerra, o que contribuiu para a criação da ESG, segundo o general Cordeiro de Farias (1981). A ida do General César Obino, ao National War College (EUA), para avaliar a possibilidade de implantação daquele modelo de formação aos militares brasileiros, seguiu-se de uma visita da missão estadunidense ao Brasil entre setembro e outubro de 1948, para organizar a formação do Estado Maior. Os EUA mantiveram um oficial como parte do corpo docente permanente na ESG até os anos 1970 (ROCHA, 1996).

A influência militar estadunidense na América Latina se fez sentir gradualmente, à medida que se tornava uma potência. Para Griffiths Spielman, a Doutrina Monroe, ainda em 1823, foi uma primeira diretriz militar continental: vetava a interferência europeia, caso se chocasse com os interesses 
estadunidenses. Em 1904, o corolário Theodore Roosevelt (ou "Big Stick") era a declaração do monopólio da violência daquele país sobre o continente, especialmente sobre a América do Norte e Central (GRIFFITHS SPIELMAN, 2011, p. 83).

Com a Crise de 1929, os EUA visaram os mercados latino-americanos para seus produtos, daí se esforçaram para convencer os trabalhadores latinoamericanos de que a saída bolchevique não era a melhor resposta à crise. Assim, a partir de 1933, a Política da Boa Vizinhança diversificou as estratégias de aproximação estadunidenses.

O período de vigência da política da Boa Vizinhança, dos anos 1930 até o final da Segunda Guerra, caracterizou-se pela intensificação do anticomunismo e do discurso da segurança hemisférica. Nesta época, aconteceu uma “divisão de tarefas" entre os militares latino-americanos e estadunidenses: os primeiros se ocupavam cada vez mais do tema da segurança, enquanto os segundos dedicavam-se à defesa. São marcos desta nova tarefa: a Conferência Especial Interamericana para a Manutenção da Paz (1936), a Junta Interamericana de Defesa (1942), o Tratado Interamericano Assistência Recíproca (TIAR) e o National Security Act (ambos de 1947).

Nesse quadro da Guerra Fria, no mesmo ano de 1947, despontou nos EUA a doutrina Truman, que reforçava a defesa do "mundo livre" contra o “totalitarismo comunista”. Surge então uma "estratégia de guerras limitadas e locais”, cujo principal instrumento era o conceito de "segurança nacional" visando a combater o comunismo em outros países (TAPIA VALDÉS, 1980, p. 49).

Para Tapia Valdés (1980), na segunda metade dos anos 1950, a política externa dos EUA se militarizou devido a três fatores: a) avanço tecnológico militar e, com a ameaça de uma guerra nuclear, a diplomacia passou a ser instrumento principal para impor interesses; b) a ascensão de novos atores no cenário internacional: China Comunista, o Bloco Europeu e o "Terceiro Mundo" e, por último, c) a difusão do ideário de democracia e igualdade social, a partir da criação da ONU, ganhou uma tribuna internacional.

Após a Revolução Cubana e o fracasso das tentativas estadunidenses de arrefecê-la (inclusive pela violência em 1961, no caso Playa Girón), os EUA lançaram uma nova frente de combate ao comunismo, incentivando o desenvolvimento nos marcos do capitalismo: era a Aliança para o Progresso. Todavia, em troca dos investimentos prometidos pelo programa, segundo Griffiths Spielman, a América Latina deveria aderir à DSN. O militar chileno 
destacou que a DSN e a Aliança para o Progresso tinham o objetivo de combater o comunismo no continente, reforçando a ideia de segurança hemisférica, especialmente treinando as diversas Forças Armadas para combaterem conflitos de "baixa intensidade” (GRIFFITHS SPIELMAN, 2011). O problema de identificar na Revolução Cubana o estopim das políticas de segurança interna, como fez Griffiths Spielman, é minimizar eventos como a “intentona” comunista de 1935 no Brasil ou o levante de Trujillo em 1932 no Peru, que mostram que o anticomunismo dos militares latino-americanos antecedia a Revolução Cubana.

Segundo dados apresentados por Tapia Valdés (1980), Rodríguez Beruff (1983) e Griffiths Spielman (2011), Brasil e Peru foram os países que mais receberam ajuda militar estadunidense para a contenção de guerrilhas. $O$ jurista Tapia Valdés (1980) informa que, entre 1950 e 1976, 8657 brasileiros e 7201 peruanos foram treinados pelo South Command no Canal do Panamá; os dois países também foram os que mais receberam ajuda militar financeira: até 1966, o Brasil recebeu 374 milhões de dólares; enquanto o Peru, 134,3 milhões de dólares; entre 1965 e 66, os montantes cresceram consideravelmente, o Brasil recebeu neste biênio 579 milhões de dólares e, o Peru, 187,6 milhões de dólares. Tapia Valdés inclusive teceu a seguinte relação entre o desenvolvimentismo da Aliança para o Progresso e a DSN: o objetivo dos investimentos estadunidenses em infraestrutura e industrialização eram dar sustentabilidade à repressão (TAPIA VALDÉS, 1980).

Tapia Valdés (1980), assim como Dreifuss (1981), enfatizam o uso do treinamento “técnico” para doutrinação política. A “inoculação do american way of life" seria feita pela sociabilidade, além da reiteração de ideias como "incompetência” civil e fraqueza das democracias para conter o comunismo. No entanto, militares brasileiros e peruanos não eram tábulas rasas, nos quais estas ideias entrariam sem a mínima conivência ou problematização.

Rodríguez Beruff indicou que entre 1950 e 1968, 5671 oficiais brasileiros e 4444 oficiais peruanos foram treinados por estadunidenses, incluindo treinamentos oferecidos dentro destes países, sem contar os créditos cedidos para o setor militar. Apesar de tanto investimento, Rodríguez Beruff não acredita que o oficialato peruano absorveu acriticamente as posições estadunidenses: incorporavam-nas à medida que serviam para legitimar a sua própria DSI (RODRIGUEZ BERUFF, 1983).

Apesar da "ajuda” militar, cujos montantes só perdiam para os brasileiros, os militares peruanos tinham uma relação distanciada de seus pares 
estadunidenses. Rodríguez Beruff, Toche Medrano e Kruijd, cada um a seu modo, compararam a influência que franceses e estadunidenses tiveram na formação militar dos peruanos, especificamente, na geração do golpe de 1968.

A reserva em relação aos estadunidenses ficou clara em 1965, quando durante o combate às guerrilhas do ELN - Ejercito de Liberación Nacional - e do MIR - Movimiento de Izquierda Revolucionário - o Exército requisitou napalm aos norte-americanos, que se recusaram a fornecê-lo. De modo que os peruanos decidiram pressionar a International Petroleum Company (IPC), instalada no país para produzir a arma (MASTERSON, 2001; RODRIGUEZ BERUFF, 1983; VILLANUEVA, 1971).

A doutrina da guerra revolucionária ensinada nos anos 1950 e 1960 era também de origem francesa. Esta nova doutrina se constituiu durante a experiência francesa de luta no Vietnã e na Argélia, e foi utilizada, junto ao ideário estadunidense da segurança hemisférica, para fomentar o golpismo militar na América Latina.

Segundo o artigo de Martins Filho A influência doutrinária francesa sobre os militares brasileiros nos anos 1960, quando os estadunidenses declaradamente se engajaram na luta antissubversiva em 1962, militares brasileiros e argentinos - e também os peruanos - já estariam familiarizados com o tema (MARTINS FILHO, 2008). Mas, lembremos que os estadunidenses já derrubavam governos acusados de comunismo, como no caso do reformista Jacobo Arbenz na Guatemala, em 1954.

Martins Filho explica que a partir de 1954, com a derrota em Dien-Bien-Phu e do início da Guerra na Argélia (ambos no mesmo ano do golpe na Guatemala), o Exército francês formulou uma nova doutrina militar focada nos combates coloniais - era a doutrina de Guerra Revolucionária (MARTINS FILHO, 2008). O marco da entrada de tal doutrina na ESG foi a conferência do coronel Augusto Fragoso em 1959, e, no CAEM, o primeiro manual encontrado sobre este tema foi numa conferência de 1959, traduzida de um artigo publicado em 1957.

Esta doutrina, assim como a da guerra total, também contribuiu para certo apagamento - numa só via - de fronteiras entre militares e civis, à medida que legitimava àqueles a se apropriarem de tarefas destes a título de combaterem a subversão. Outra vantagem da doutrina da guerra revolucionária para os militares latino-americanos era colocá-los no centro da Guerra Fria.

Assim, as guerras total e revolucionária se complementavam: se a primeira permitia aos militares organizar os meios materiais (indústria, estradas, infraestrutura etc.), e imateriais (patriotismo, orgulho) para a guerra, a segunda 
transpunha o conflito para plano o interno, colocando a própria população como alvo, caso demonstrasse insatisfação com o capitalismo. Dessa forma, a doutrina de guerra revolucionária, desenvolvida para conter as rebeliões nas colônias francesas, encontrou terreno fértil no ambiente da Guerra Fria fomentado pelos EUA na América Latina.

Para Rodrigo de Araújo (2009), a formulação da doutrina de guerra revolucionária pelos franceses foi uma estratégia de reconquista do mercado latino-americano. Para Araújo, a doutrina francesa foi fruto de uma reflexão dos oficiais sobre a derrota que sofreram na Indochina, a partir da qual valorizaram as ações cívicas, enfatizaram a guerra psicológica, e incluíram o policiamento nas funções militares. Portanto, a doutrina militar francesa harmonizouse com a doutrina militar estadunidense. Vejamos agora como cada uma das escolas militares construiu a própria doutrina a partir de tais referências e de suas análises conjunturais.

\section{Segurança Integral x Segurança Nacional: duas soluções para o mesmo problema}

As doutrinas militares elaboradas tanto na ESG quanto no CAEM mudaram ao longo das décadas de 1950 e 1960, isto é, desde a fundação das escolas militares até os golpes. A partir das conferências ministradas no CAEM e na ESG, compararemos o conteúdo destas doutrinas, destacando como expõem as ideias a respeito da sociedade e de suas instituições.

Em maio de 1949, o general Osvaldo Cordeiro de Farias, palestrou aos oficiais na Escola de Estado Maior, para esclarecer os motivos da abertura da ESG. Sua exposição discorreu sobre o sucesso estadunidense em unir militares e civis para solucionar problemas postos pela guerra na era da produção industrial. $\mathrm{O}$ palestrante explicou ainda que a abertura da escola estava em consonância com a Constituição de 1946, especificamente o artigo 179 - que tratava do Conselho de Segurança Nacional, e com o Tratado Interamericano da Assistência Recíproca (TIAR, assinado em setembro de 1947), pois, na nova escola, o foco seria a segurança nacional - primeiro dever do Estado para o general. Na explanação do general Farias, aparecem como pilares da SN assuntos nacionais (planejamento para desenvolvimento), assuntos internacionais (coordenação com segurança do hemisfério ocidental) e assuntos militares (coordenação das três armas e mobilização), que formaram os três departamentos iniciais da ESG. Nessa palestra, salta aos olhos a imersão na disputa da Guerra Fria e a 
posição de submissão do Ocidente em relação ao "irmão" do norte: "O mundo Ocidental gira hoje em torno da América do Norte”

Já em julho de 1945, o general José del Carmen Marín Arista discursou no Círculo Militar do Peru sobre a necessidade da elaboração de uma doutrina de guerra que respondesse aos desafios da guerra na era industrial. Para o general Marín, o Estado tinha as seguintes responsabilidades, tão importantes quanto a defesa: “liberdad económica, progreso y bienestar materiales de la Nación”. Nesta exposição, referiu-se sempre à defesa da pátria, não à segurança, o que denota sua prioridade com possíveis ameaças externas, objetivo tradicional das Forças Armadas, e não internas, potencializadas pelo tema da segurança hemisférica via EUA (MARÍN ARISTA, 1949, p. 7, grifo nosso). Destaca-se ainda a diferença de prioridades do Estado entre os generais Cordeiro de Farias e Marín: se para o primeiro sua principal atribuição era a segurança, para o segundo a liberdade econômica, progresso e bem-estar material da nação - entendida aqui como a população; é interessante verificar que, para o general peruano, a segurança é uma consequência do progresso material e não um fim em si mesma.

O general Marín, em sua exposição, entra no tema dos diversos problemas sociais do Peru e os relaciona à defesa do país. Assim, o desenvolvimento seria a solução dos problemas sociais e a base da força da mobilização necessária para a defesa da pátria, afinal, para o general, ninguém defenderia um país onde não vive bem. Quanto ao posicionamento internacional, o general Marín, diferentemente do general Cordeiro de Farias, não aponta o Peru como aliado $a$ priori de nenhuma nação, ao contrário, afirmou que a situação internacional se constituía de cenários variáveis e que cabia à chancelaria de seu país avaliar e identificar possíveis aliados ou concorrentes (MARÍN ARISTA, 1949).

Para o fundador do CAEM, o bem-estar era condição necessária para a segurança e, ao mesmo tempo, objetivo desta, o que resultaria numa elaboração doutrinária que considerava a qualidade de vida da população como fator de segurança. O general Marín via a Guerra Fria como um risco à soberania dos Estados nacionais, objetos da disputa de interesses das duas potências. De um lado, a potência capitalista, que não desejaria a autonomia econômica dos Estados, de outro, a potência comunista não desejaria a autonomia política dos Estados não comunistas e, para destruí-los, alimentariam a subversão interna. A leitura do general Marín sobre aquele conflito que dilacerou as nações periféricas na segunda metade do século XX é muito distante daquela feita pelo general Cordeiro de Farias e outros oficiais da ESG. Por mais que fosse anticomunista, Marín conseguia separar anticomunismo e submissão aos Estados Unidos, ao 
contrário de seu colega brasileiro, para quem a filiação ao hemisfério cristão ocidental estava acima de qualquer autonomia, e qualquer reivindicação desta poderia ser identificada como adesão ao comunismo (especialmente dentro do país).

Uma fonte importante para compreender a doutrina da ESG é a obra do desembargador Antonio Arruda, A Escola Superior de Guerra, espécie de "história oficial" da ESG, pois o objetivo do autor - ex-estagiário e membro do corpo permanente - era difundir o pensamento da instituição. Nesta obra, o autor enfatizou que a doutrina esguiana era antidogmática, inspirada em princípios democráticos e humanistas, pois seu objetivo seria o bem comum (tal qual no CAEM). Arruda (1983) explicou que, durante seus primeiros anos (1949-1952), o foco da escola foi o estudo da conjuntura e, apenas em 1953, a doutrina passou a ser o centro dos estudos. Neste ano, o general Juarez Távora, comandante da escola, propôs uma definição de segurança nacional baseada em manuais estadunidenses e no ano seguinte, o General Távora anunciou uma definição própria da doutrina de segurança nacional nos seguintes termos:

\begin{abstract}
grau relativo de garantia que, por meio de ações políticas (internas e externas) econômicas, psicossociais (inclusive atividades técnico-científicas) e militares -, um Estado proporciona à coletividade que jurisdiciona, para a consecução e salvaguarda de seus objetivos nacionais, a despeito dos antagonismos existentes. (TÁVORA, 1954, p. 20)
\end{abstract}

Percebemos que a definição doutrinária antecedeu a elaborada pelo general Golbery, apesar de este ter sido seu maior divulgador em meios civis, por sua intensa atividade em institutos como o IPES e o IBAD - Instituto de Pesquisas Sociais e Instituto Brasileiro de Ação Democrática -, além da própria ESG. Segundo Arruda (1983), esta definição da DSN permaneceu até 1959, quando o próprio general Távora a alterou: trocou a expressão "ações políticas e militares" por "político-administrativas" - inserindo as Forças Armadas na esfera política.

Na apostila da turma do CAEM de 1967, encontra-se a informação de que a doutrina em voga foi elaborada pela turma de 1963. A doutrina era definida no CAEM como:

conjunto de principios y su consecuente teoría que, aplicados a 
un medio determinado, teniendo en cuenta sus características y peculiaridades, genera métodos y procedimientos que norman las acciones destinadas a alcanzar una finalidad específica. (CAEM, 1963, p. 1)

A doutrina de "bem-estar geral" estava acima das demais e era uma diretiva do Estado; assim consistia na "doutrina de defesa nacional", que tinha como objetivo a segurança integral, isto é, em seus quatro níveis (diplomático/ político, econômico, psicológico e militar). E desta doutrina de defesa nacional derivavam as doutrinas de guerra e das Forças Armadas. A doutrina de bemestar geral consistia em:

conjunto de principios de Bienestar General y su consecuente teoría, que aplicados a una nación determinada, teniendo en cuenta sus características y peculiaridades, genera directivas, métodos y procedimientos que norman las acciones destinadas a alcanzar la satisfacción adecuada y oportuna de las necesidades espirituales y materiales de la persona humana, tanto de carácter colectivo como individuales, previendo las futuras. (CAEM, 1963, p. 1)

Nesta doutrina do CAEM, que difundida desde 1963 até, pelo menos, 1967, também consta a ideia de que todas as nações buscam o bem comum, ainda que de diferentes pontos de partida. Tal ideia exposta em plena Guerra Fria sinalizava um espaço para diálogo com países que se orientassem por outros tipos de organização política.

Segundo o livro 50 años del $C A E N^{3}$, a construção de uma doutrina militar que considerasse as condições nacionais e, ao mesmo tempo, o avanço industrial, tecnológico e estratégico ocasionado pelas guerras mundiais era o principal propósito desta instituição. Para tanto, o General Marín e seus continuadores dedicaram-se inicialmente a investigação do potencial nacional - capacidade de geração de recursos -, primeiro do ponto de vista militar e, depois, de todo o Estado. Nesta obra, publicada pelo departamento de História do Exército, defesa nacional aparece como:

responsabilidad de todos os peruanos y que el fin primordial del Estado era la obtención del Bién Común que implicaba el Bienestar y Seguridad, cuya interrelación e interdependencia quedaba claramente establecida 
y se convirtieron en el sustento doctrinario de la Defensa Nacional. (CAEN, 2000, p. 50)

Na mesma obra, a doutrina de segurança integral foi definida da seguinte forma:

El Bienestar General es definido como la situación en la cual las necesidades espirituales y materiales de la colectividad se satisfacen plenamente y en forma adecuada y oportuna. La Seguridad Integral es la situación en la cual el Estado tiene garantizada su existencia e integridad de su patrimonio, así como la facultad de actuar con autonomía en el campo interno y libre de toda subordinación en el campo externo. [...]. Para la doctrina del CAEM, el más alto grado de bienestar de una nación es la mejor garantía para la solidez de su frente interno. Sin bienestar no es posible pretender una seguridad nacional. Un país débil no puede sostener un ejército poderoso. (CAEN, 2000, p. 64)

Cabe destacar uma importante mudança em relação ao texto de 1963: de “defesa nacional ou bem estar" a doutrina passou a ser de "segurança integral”, o que mostra que as ameaças a serem combatidas passaram para dentro do território nacional, como o “inimigo interno”. A alteração pode ser explicada porque, depois de 1963, as Forças Armadas peruanas enfrentaram movimentos guerrilheiros em dois momentos: em 1965 e de 1980 a 1992, que os teriam direcionado ao tema da segurança interna.

Nas duas definições doutrinárias do CAEM, de 1963 e na publicada no livro oficial da história da instituição em 2000, aparecem dois elementos centrais que são periféricos na doutrina da ESG: a ideia de bem comum e coletividade.

Na ESG, o bem comum, de acordo com Arruda (1983, p. 85), é objetivo da nação, mas está subordinado à segurança, esta sim prioritária. Enquanto a "coletividade nacional”, para a ESG, era apenas objeto da ação do Estado, no CAEM deveria ter suas "necessidades materiais e espirituais plenamente satisfeitas de forma adequada e oportuna". O modo de abordar a "coletividade" demonstra como as populações das duas nações eram vistas pelas academias militares. Se na ESG a população era objeto de ação do Estado, no CAEM, a população deveria ser atendida em suas necessidades.

Tanto na ESG como no CAEM as necessidades eram reconhecidas, mas nos dois casos a população não era vista como sujeito ativo. Tal leitura sobre a 
população deve-se a uma herança da "missão civilizatória" que os militares brasileiros e peruanos se autoincumbiram no final do Século XIX: o indígena ou camponês no Peru, e o caboclo ou o sertanejo no Brasil, não eram sujeitos, mas vítimas da história.

\section{Atuação política da ESG}

Os anos de 1954 e 1955 foram emblemáticos para a ESG: a instituição ganhou os holofotes capitaneando o antigetulismo, e após as manifestações populares que se seguiram ao suicídio do presidente Vargas e, no ano seguinte, o golpe "preventivo" do general Lott, que garantiu a posse de Kubitschek, teve que moderar sua exposição política temporariamente. Naquele momento, segundo Ferraz, a relação entre civis e militares na ESG passou a ser vista por parte do oficialato, como foco de indisciplina e de estabelecimento de um grupo de poder paralelo dentro da instituição; por isso, o comandante do Estado Maior, general Anor Teixeira dos Santos - que cursou a ESG em 1952 -, propôs que esta instituição fosse exclusiva para militares e que os civis que quisessem discutir planejamento e desenvolvimento nacional cursassem o ISEB - Instituto Superior de Estudos Brasileiros. Tal proposta foi derrotada após ampla mobilização dos ex-estagiários civis instalados nos três poderes e nas Forças Armadas (FERRAZ, 1997).

Vânia Aderaldo mencionou outra tentativa de mudança da ESG: da esfera militar, ou seja, da subordinação aoEstado Maior das Forças Armadas, para colocála sob controle civil no Conselho de Segurança Nacional, para que ampliasse seus debates para "temas mais genéricos referentes ao fortalecimento do poder nacional". Para a autora, este debate sobre a "subordinação administrativa da ESG" indica que havia um descompasso entre seus "propósitos doutrinários e políticos" e sua condição de instituição militar, que limitaria seu raio de ação doutrinadora (ADERALDO,1978, p. 104) Contudo, era justamente a condição de instituição militar que permitia aos seus membros se organizarem politicamente em nome de propósitos “universais" como o bem-estar, o progresso da nação e o anticomunismo. Segundo Ferraz (1997), a instituição se organizou como partido, sem arcar com o ônus público de ser apresentada como tal.

Em 1955, a conferência “A Segurança Nacional e a ESG”, proferida pelo então comandante da instituição, o vice-almirante Ernesto de Araújo apresentou os conceitos básicos da ESG, a saber: objetivo nacional, poder nacional e segurança nacional. 
No âmbito interno, organizamos e almejamos manter um Estado democrático e cristão em que, reconhecidos os direitos naturais do homem e respeitada sua dignidade, é possível estabelecer um ambiente de paz e justiça social e no qual, dentro da ordem e da lei, se deve propiciar a todos, sem distinção de raça, credo ou classe, um constante progresso no sentido de um máximo de bem-estar, moral e material. (ARAÚJO, 1955, p. 3)

Nesta descrição dos objetivos nacionais saltam aos olhos o ideário liberal e sua defesa dos “direitos naturais” e a contradição entre um “Estado democrático e cristão” e a "indistinção de credo”. Além disso, os objetivos, ditos nacionais, eram debatidos num ambiente cujos presentes não tinham representatividade nacional. A seguir, as definições doutrinárias de segurança nacional e poder nacional:

\footnotetext{
Torna-se, pois, necessário garantir a consecução e a manutenção do Objetivo Nacional, utilizando racionalmente contra esses antagonismos o Poder Nacional, isto é, o poder resultante da composição harmônica dos poderes de que dispõe o Estado em cada campo de atividade. A essa garantia se dá o nome de Segurança Nacional e ao plano geral de aplicação do Poder Nacional para atingi-la em grau satisfatório, pois a garantia absoluta é ideal inatingível, constituirá a Política de Segurança Nacional. Fixar uma Doutrina e estabelecer um método de planejamento que permitam a formulação de uma adequada política de segurança, eis o objetivo, fixado pelo regulamento, dos estudos da Escola. (ARAÚJO, 1955, p. 3-4, grifos do autor)
}

Verifica-se como a ideia de segurança nacional era compreendida: como garantia da manutenção do estado liberal, apresentado como objetivo nacional; sendo que cabia a ESG elaborar métodos e planos que possibilitassem alcançar tal garantia.

\section{Atuação política do CAEM}

No Peru, o biênio de 1962-63 foi marcado por uma primeira experiência de governo militar reformista. O general Ricardo Perez Godoy derrubou o governo de Manuel Prado em seus últimos dias, devido às circunstâncias em que seria decidido o segundo turno das eleições de seu sucessor: em votação indireta, no congresso nacional, numa possível aliança entre o APRA e a UNO, levaria Odría 
e os conservadores de volta ao governo, desta vez aliado ao APRA, apesar de todo seu passado de lutas sociais, agora tomado por um pragmatismo político extremo, que não atraiu o apoio militar

Foi naquele momento que as elaborações doutrinárias do CAEM ganharam projeção pública, com a criação do Instituto Nacional de Planificación e com a reforma agrária no Valle de La Convención, Cuzco, onde os sindicatos camponeses organizados por Hugo Blanco ocuparam metade dos latifúndios, mesmo com a grande onda migratória da serra para o litoral.

No CAEM, as conferências sobre segurança integral continham um conjunto de conceitos similares aos da ESG brasileira (objetivos nacionais, potencial nacional, defesa nacional, entre outros) no entanto, percebemos uma preocupação maior com os problemas da população pelo modo como formularam tais conceitos.

No mesmo ano de 1962, o engenheiro Jorge Bravo Bresani proferiu a conferência "Princípios y teoria para la determinación de objetivos nacionales de un Estado". Nesta conferência, Bravo Bresani definiu o objetivo nacional da seguinte forma:

Todo Objetivo Nacional se postula pues como una carencia, sentida como tal, es decir, que la población, el conjunto del país siente que hay algo que le falta, algo que le falta vitalmente para cumplir el concepto de bienestar, tal como, en ese momento lo concibe y siente la población. (BRAVO BRESANI, 1962, p. 1)

Tal definição se diferencia em muito daquela que aparece nos manuais da ESG. No CAEM peruano o centro do objetivo nacional é o que falta à população; o povo ocupa um lugar central na exposição proferida na Escola militar para pensar uma doutrina de defesa e desenvolvimento nacional.

A definição do objetivo nacional da ESG, feita pelo seu segundo comandante Juarez Távora foi formulada nos seguintes termos:

objetivos nacionais são realidades ou aspirações, relacionadas com a integração física, política, econômica ou social de uma nação, e que, consubstanciados objetivamente no espírito da elite, se transmitem à sensibilidade do povo-massa como hábitos ou necessidades unânimes ou generalizados da coletividade nacional. (TÁVORA, 1959, p. 4) 
Ao compararmos as duas definições, ambas tratam de algum modo do hiato entre o que a nação "tem" e o que "lhe falta". A grande diferença era que, para o engenheiro peruano Bravo Bresani, esta falta era sentida, sobretudo, pela população em busca de seu "bem-estar"; por outro lado, para o comandante brasileiro Juarez Távora, os objetivos nacionais deveriam servir para integrar a população ao Estado nacional, e serem formulados primeiramente pelas elites para depois serem transmitidos ao povo.

O que mais se destaca na conferência de Bravo Bresani é a maneira como os objetivos nacionais deveriam ser elaborados, de modo muito distinto daquele proposto na ESG. Tal elaboração começa pelo reconhecimento da existência de diversos indivíduos e grupos com interesses distintos e até mesmo divergentes no Estado nacional, e que os objetivos de cada grupo primeiro deveriam ser reconhecidamente políticos, isto é, serem legitimados pelo espaço público e depois, para se tornarem nacionais, tais objetivos deveriam convencer ampla maioria da população (BRAVO BRESANI, 1962). Assim, no CAEM a discussão política era legítima, contrariamente ao que acontecia na ESG.

Cabe mencionar outras diferenças importantes no que se refere às concepções dos objetivos nacionais que nortearam a ESG e o CAEM. Na ESG, estes objetivos nacionais eram divididos em permanentes (ONP) e atuais (ONA), sendo que os permanentes:

devem subsistir senão indefinidamente [...] ou como simples meta a ser atingida, sem prazo determinado e seriam de natureza política, como a unidade territorial ou sobrevivência da nação, por exemplo. Os objetivos atuais seriam as necessidades ainda não satisfeitas, mas [...] ao alcance do poder nacional [...] e seriam de 'natureza estratégica'. (TÁVORA,1959, p. 5)

Assim, para a ESG, os objetivos nacionais permanentes, ou seja, políticos, elaborados pela elite, não abriam espaço para a população decidir, por exemplo, sobre a permanência da configuração nacional e, por outro lado, os objetivos atuais ou estratégicos, que dependeriam de uma avaliação de conjuntura, não colocavam em pauta as aspirações populares.

Muito diferente desta concepção esguiana, no CAEM, o professor Bravo Bresani reconhecia que todo objetivo nacional deveria ser uma espécie de pacto provisório de unidade, sempre renegociado a cada troca de governo. Sendo assim, é necessário mostrar a articulação das ideias presentes na instituição 
e que culminam na formulação dos objetivos nacionais. Em primeiro lugar, a ideia de que as instituições do Estado, assim como os tais objetivos nacionais, são frutos de disputas de diversos grupos, portanto são pactos necessariamente provisórios, cuja duração está atrelada às condições de sua elaboração.

Outro tema importante é a ideia de que há os objetivos nacionais institucionalizados, ou melhor, aqueles dos quais se ocupa o Estado, e outros objetivos que são políticos e legítimos, mesmo quando não incorporados pelo Estado. Tal incorporação seria uma questão de disputa política, o que significava reconhecer o espaço da sociedade nas lutas políticas, o que não acontecia com relação à ESG.

Para o CAEM, o objetivo nacional era uma forma de valorizar os interesses mais gerais em detrimento das divergências entre os grupos, reconhecendo a existência e a permanência destes e assim, a própria democracia.

Nessa mesma exposição, Bravo Bresani diferenciou os países entre integrados e desintegrados: os primeiros seriam aqueles com claros objetivos nacionais, geralmente desenvolvidos, nos quais, apesar das divergências e disputas políticas, os objetivos nacionais seriam mais coesos e próximos a unanimidade; os exemplos de nações integradas, dados por Bravo Bresani, foram a Alemanha Ocidental, a União Soviética (URSS) e os EUA. Por outro lado, as nações desintegradas seriam aquelas subdesenvolvidas, entre as quais estava o Peru. Nestas, os grupos políticos teriam objetivos completamente diferentes e, muitas vezes, profundamente divergentes. Nestes contextos, os obstáculos apontados pelo autor para que os objetivos nacionais fossem construídos eram nesta ordem: “a ignorância das massas, a anarquia ideológica dos dirigentes e os pujantes interesses contrários ao interesse coletivo” (BRAVO BRESANI, 1962, p. 6).

Para o autor, as disputas para a construção de objetivos nacionais dividiam as sociedades em dois grandes grupos: progressistas e "partidários do estancamento", de modo que, ao final, os primeiros se aliariam à "massa primitiva” para lutar pelo que deveria ser o máximo objetivo nacional: “[...] la solidaridad con los oprimidos para alcanzar el desarrollo general del país con su colaboración” (BRAVO BRESANI, 1962, p. 8). Esta leitura de Bravo Bresani, que pressupunha um alinhamento entre "primitivos” e "progressistas", era uma interpretação da sociedade tão otimista quanto àquela feita no Brasil por membros do ISEB, que acreditavam na existência de uma burguesia nacional, que se aliaria às classes trabalhadoras para a implantação de um projeto modernizador democrático. 
O professor do CAEM afirmou ainda que havia duas formas de realizar os objetivos nacionais: a via revolucionária, na qual o povo ascenderia ao governo para realizá-los; e a via da colonização, na qual uma minoria imporia transformações à população que, ao perceber melhorias em sua condição aderiria aos novos princípios. Ao término de sua exposição, Bravo Bresani (1962) defendeu que para determinar os objetivos nacionais, caberia fazer uma ampla "pesquisa de ordem cultural-sociológica” para identificar quais as “aspirações gerais das gentes”, suas raízes e motivações, e quais os recursos disponíveis para a realização de tais aspirações depois que fossem estabelecidos nexos entre as estruturas de poder e organização social vigentes e os "níveis de vida” encontrados e, a partir de então, verificar o que fazer com os recursos disponíveis. Acrescentou ainda que, a partir dos objetivos nacionais, começaria o trabalho de planejamento.

Segundo Bravo Bresani (1962), para que os objetivos fossem realizados pela via da planificação a longo prazo, sem que fossem impostos pela colonização, mas pela revolução - via espontânea - seria necessário que o plano fosse construído sobre uma “consciência coletiva” que, por ser heterogênea nas sociedades, caberia àqueles mais conscientes informar os menos conscientes. Ao fim e ao cabo, o planejamento visaria a "satisfazer as necessidades do povo", o grande objetivo nacional (BRAVO BRESANI, 1962, p. 11).

\section{Considerações finais}

Pelo exposto, verificamos que as doutrinas militares pensadas no Brasil e no Peru, a partir das influências estadunidenses e francesas resultaram em concepções bem diferentes acerca dos meios de elaboração e dos conteúdos dos objetivos nacionais. A influência das ideias francesas, tanto de guerra total como de guerra revolucionária, estiveram presentes no CAEM e na ESG, e foram incorporadas de formas diferentes.

No CAEM, a influência francesa foi mais duradoura e profunda e contribuiu para a construção de um ideal civilizatório, que consistia na ideia de que o Exército deveria exercer o protagonismo na ocupação dos territórios do interior e na formação do cidadão peruano. A instituição absorveu também o método francês de avaliação da conjuntura, especialmente pelos generais Marín Arista e Pardo Marcial. Esse olhar mais cartesiano para a realidade resultou numa avaliação mais equidistante das disputas da Guerra Fria, pois fica claro que no CAEM, por mais que reverberasse o anticomunismo, como em todo continente, 
exceto em Cuba pós 1959, a sombra do imperialismo era vislumbrada a partir da percepção do interesse estadunidense na defesa do Hemisfério ocidental, explicitado nos treinamentos e nos empréstimos direcionados a este fim.

Na ESG, a posição política dada a priori, antes mesmo da abertura desta instituição devido a experiência da FEB na Segunda Guerra, suplantou inicialmente uma possível desconfiança acerca da postura imperialista estadunidense, manifesta por meio de treinamentos e empréstimos. Diferentemente dos peruanos do CAEM, foi a proximidade dos estadunidenses que despertou os militares brasileiros para a importância do desenvolvimento industrial, e do desejo de elevar o Brasil a condição de potência; era preciso planejar de modo "correto" os meios de explorar os recursos disponíveis e contar com o reconhecimento dos serviços prestados na defesa do hemisfério.

No Brasil, a opção política pelo posicionamento em relação ao "hemisfério ocidental liberal, cristão e capitalista" antecedeu e, portanto, contribuiu para a construção da doutrina militar com todos os seus desdobramentos. Já no Peru, foi a crítica às elites políticas que sustentou a doutrina de segurança integral. Os peruanos do CAEM acreditavam na "neutralidade" da técnica para superar as "disputas de interesses particulares" do político, resultando no objetivo almejado por todos os peruanos: havia a crença real de que existia uma técnica neutra, que aplicada com competência, levaria ao desenvolvimento do país, alcançando principalmente as massas.

Conforme mostramos, entre os anos 1950 e 1960, houve na ESG brasileira e no CAEM peruano, uma fusão original entre as teorias da guerra total e da guerra revolucionária, vindas da França e dos Estados Unidos, que contribuíram para a formulação de doutrinas diferentes: no Brasil, a doutrina de segurança nacional e no Peru, a doutrina de segurança integral.

\section{Referências}

ADERALDO, Vanda Maria Costa. A escola superior de guerra: um estudo de currículos e programas. 1978. Dissertação (Mestrado em Ciência Política) Universidade do Estado do Rio de Janeiro, Rio de Janeiro, 1978.

ARAÚJO, Ernesto de. A segurança nacional e a ESG. Rio de Janeiro: ESG, 1955.

ARAÚJO, Rodrigo Nabuco. A influência francesa dentro do Exército brasileiro (1930-1964): declínio ou permanência? Esboços-Revista do Programa de PósGraduação em História da UFSC, Florianópolis, v. 15, n. 20, p. 245-273, 2009. 
ARRUDA, Antonio de. A escola superior de guerra. 2. ed. São Paulo: GRD; Brasília: Instituto Nacional do Livro, 1983.

BRAVO BRESANI, Jorge. Principios y teoria para la determinación de objetivos nacionales de un estado. Lima: CAEM, 1962.

CAEM - CENTRO DE ALTOS ESTUDIOS MILITARES. Doctrina de bienestar general: conferencia. Lima: CAEM, 1963.

CAEN - CENTRO DE ALTOS ESTUDIOS NACIONALES. 50 años del CAEN. Lima: CAEN, 2000.

CARVALHO, José Murilo. Forças armadas e política no Brasil. Rio de Janeiro: Jorge Zahar, 2005.

COELHO, Edmundo Campos. Em busca de identidade: o exército e a política na sociedade brasileira. 2. ed. Rio de Janeiro: Record, 2000.

COMBLIN, Joseph. A ideologia da segurança nacional: o poder militar na América Latina. Tradução de Veiga Fialho. 3. ed. Rio de Janeiro: Civilização Brasileira, 1980.

DREIFUSS, René Armand. 1964: a conquista do estado. Tradução de Else Ribeiro Pires Vieira. 3. ed. Petrópolis: Vozes, 1981.

FARIAS, Osvaldo Cordeiro de. Meio século de combate: diálogo com Cordeiro de Farias. [Entrevista cedida a] Aspásia Camargo e Walter de Góes. Rio de Janeiro: Nova Fronteira, 1981.

FERRAZ, Cesar Francisco Alves. À sombra dos carvalhos: a Escola Superior de Guerra e política no Brasil: 1948-1955. Londrina: Editora da UEL, 1997.

FRAGOSO, Augusto. Introdução ao Estudo da Guerra Revolucionária. Rio de Janeiro: ESG, 1959.

GRIFFITHS SPIELMAN, Jonh E. Teoría de la seguridad y defensa en el Continente Americano. Santiago: RIL, 2011.

HUNTINGTON, Samuel P. O soldado e o Estado: teoria e política das relações entre civis e militares. Tradução de José Lívio Dantas. Rio de Janeiro: Biblioteca do Exército, 1996.

KRUIJT, Dirk. La revolución por decreto: el Perú durante el gobierno militar. 2. ed. 
Lima: INP, 2008.

LEAL BUITRAGO, Francisco. La doctrina de Seguridad Nacional: materialización de la Guerra Fría em America del Sur. Revista de Estudios Sociales, Madrid, v. 15, p. 74-87, 2003.

MARÍN ARISTA, José del Carmen. Nociones sobre las bases en que reposa el proceso preparación integral de las fuerzas vivas y las Fuerzas Armadas de la nación. Ciclo de Conferencias en El Círculo Militar Del Perú, Lima, 1949.

MARÍN ARISTA, José del Carmen. La defensa nacional: conceptos básicos. Lima: CAEM, 1972. Centro de Altos Estudios Militares.

MARTINS FILHO, João Roberto. A influência doutrinária francesa sobre os militares brasileiros nos anos de 1960. Revista Brasileira de Ciências Sociais, São Paulo, v. 23, n. 67, p. 39-50, 2008.

MASTERSON, Daniel. Fuerza Armada y sociedad en el Perú moderno: um estudio sobre relaciones civiles y militares 1930-2000. Lima: Instituto de Estudios Politicos y Estratégicos, 2001.

MONTEFORTE TOLEDO, Mário. La solución militar a la peruana 1968-1970. México: Instituto de Investigaiones Sociales, 1973.

MORAES, João Quartim de. Desenvolvimento e legitimidade na ideologia dos militares no Brasil e no Peru. In: MORAES, João Quartim de (org.). Liberalismo e ditadura no cone sul. Campinas: Unicamp: IFCH, 2001. p. 17-56.

NUNN, Frederick.M. Professional militarism in twentieth-century Peru: historical and theoretical background to the golpe de estado of 1968. The Hispanic American Historical Review, Durham, v. 59, n. 3, p. 391-417, 1979.

OLIVEIRA, Eliezér Rizzo. As forças armadas: política e ideologia no Brasil (19641969). Petrópolis: Vozes, 1976.

OLIVEIRA, Eliezér Rizzo. A Doutrina de segurança nacional: pensamento político e projeto estratégico. In: OLIVEIRA, Eliezér Rizzo (org.). Militares: pensamento e ação política. Campinas: Papirus, 1987. p. 53-86.

OLIVEIRA, Nilo Dias de. Os primórdios da doutrina de segurança nacional: a Escola Superior de Guerra. História, São Paulo, v. 29, n. 2, p. 135-157, 2010.

PARDO MARCIAL, Romero. La guerra total. Lima: Imprensa de la Escuela Militar 
de Chorrillos, 1944.

ROCHA, Maria Selma de Moraes. A evolução dos conceitos da doutrina da Escola Superior de Guerra nos anos 70. 1996. Dissertação (Mestrado em História Social) Universidade de São Paulo, São Paulo, 1996.

RODRIGUEZ BERUFF, Jorge. Los militares y el poder: un ensayo sobre la doctrina militar em el Peru: 1948-1968. Lima: Mosca Azul Editores, 1983.

ESCOLA SUPERIOR DE GUERRA. Segurança nacional: conceitos fundamentais. Rio de Janeiro: ESG, 1963.

STEPAN, Alfred. Brasil: los militares y la política. Tradução de Inés Pardal. Buenos Aires: Amorrortu editores, 1974.

STEPAN, Alfred. Estado, corporativismo e autoritarismo. Tradução de Marina L. Teixeira, Viriato de Medeiros. Rio de Janeiro: Paz e Terra, 1980.

TAPIA VALDÉS, Jorge A. El terrorismo de estad: la doctrina de la seguridad nacional en el Cono Sur. México: Nueva Imagen, 1980.

TÁVORA, Juarez do Nascimento Fernandes. A segurança nacional e a ESG. Rio de Janeiro: ESG, 1954.

TÁVORA, Juarez do Nascimento Fernandes. A segurança nacional: sua conceituação e seu estudo na ESG. Rio de Janeiro: ESG, 1959.

TOCHE MEDRANO, Eduardo. Guerra y democracia: los militares peruanos y la construcción nacional. Lima: CLACSO/ DESCO, 2008.

VILLANUEVA, Víctor. 100 años del ejercito peruano: frustraciones y cambios. Lima: Editorial Juan Mejia Baca, 1971.

VILLANUEVA, Víctor. El CAEM y la revolución de la fuerza armada. Lima: IEP, 1972.

\section{Notas}

${ }^{1}$ Professora do curso de História da Universidade Federal do Tocantins (UFT).

${ }^{2}$ Palestra sobre a Organização da Escola Superior de Guerra, proferida por Osvaldo Cordeiro de Farias, realizada na Escola de Estado Maior no Rio de Janeiro em 18 maio 1949.

${ }^{3}$ Em 1997 passou a chamar Centro de Altos Estudos Nacionais. 